\title{
Episodic Learning and Memory in Prodromal Huntington's Disease: The Role of Multimodal Encoding and Selective Reminding
}

\author{
Tarja-Brita Robins Wahlin ${ }^{1,2}$, Åke Wahlin³, Gerard J. Byrne ${ }^{2}$ \\ ${ }^{1}$ Department of Neurobiology, Care Sciences and Society, Karolinska Institute, Stockholm, Sweden \\ ${ }^{2}$ School of Medicine, The University of Queensland, Brisbane, Australia \\ ${ }^{3}$ School of Health and Welfare, Jönköping University, Jönköping, Sweden \\ Email: tarja-brita.robins.wahlin@ki.se
}

Received 20 August 2015; accepted 27 November 2015; published 30 November 2015

Copyright @ 2015 by authors and Scientific Research Publishing Inc.

This work is licensed under the Creative Commons Attribution International License (CC BY). http://creativecommons.org/licenses/by/4.0/

(c) (i) Open Access

\section{Abstract}

This study investigated episodic memory in prodromal HD. Three groups were compared $(\mathrm{N}=70)$ : mutation carriers with less than 12.5 years to disease onset $(n=16)$, mutation carriers with 12.5 or more years to disease onset $(n=16)$, and noncarriers $(n=38)$. Episodic memory was assessed using the Fuld Object Memory Evaluation, which included multimodal presentation and selective reminding, and the Claeson-Dahl Learning Test which included verbal repeated presentation and recall trials. Both carrier groups demonstrated deficient episodic memory compared to noncarriers. The results suggest deficient episodic memory in prodromal HD, and that inconsistent retrieval contributes to these deficits. Multimodal presentation attenuates the deficits.

\section{Keywords}

Prodromal Huntington's Disease, Fuld Object Memory Evaluation, Episodic Memory, Short-Term Memory, Neurodegenerative Diseases

\section{Introduction}

Huntington's disease (HD) is an autosomal dominant, neurodegenerative disorder. It is characterized by choreic movements, psychiatric symptoms, and progressive cognitive impairment. HD is caused by an excessive number of repeats of the trinucleotide CAG in the HD gene on chromosome 4 [1], the repeat number being equal to or 
greater than 36 in individuals with HD [2]. The clinical diagnosis is typically based on a positive gene mutation test and the presence of motor symptoms [3]. Age of onset is inversely related to number of CAG repeats and is usually around 40 years, but with large variations [4] [5]. Predictive testing for HD first became available in 1983 through linkage analysis when genetic markers for the HD gene were isolated on chromosome 4 [6]. In 1993, direct mutation analysis became available by determination of the number of CAG repeats [1]. This has made it possible to study cognitive function in prodromal $\mathrm{HD}$, that is, in the phase preceding onset of manifest clinical motor symptoms and diagnosis.

Cognitive deficits have been found in psycho-motor speed, executive functions, verbal episodic memory, fluency, visuo-spatial functions, and attention about a decade before clinical disease onset [7]-[13]. Verbal episodic deficits have been detected already in prodromal HD [12]-[14], and found to worsen as the disease progresses [15] [16]. Although memory impairment is not the salient feature of HD, it affects everyday functioning [13] [17]-[19]. Memory decline is also commonly reported, by family members of mutations, as an early sign or symptom carriers in the prodromal phase of HD [20].

Episodic memory impairment is proposed to be caused by encoding and retrieval deficits [17] [21], and it has also been suggested that episodic memory impairment is secondary to executive dysfunction [22]. Earlier studies of episodic learning and memory in prodromal HD have almost exclusively used auditory verbal stimuli [12][14], but to the best of our knowledge, there are no published studies which have investigated multimodal encoding or the ability to utilize feedback in episodic learning and memory in prodromal HD. Fuld Object Memory Evaluation (FOME; [23]) has been used extensively in research on episodic memory in aging and in dementia research (e.g. [24] [25]). It is used to investigate individuals' abilities to store and retrieve from long-term memory, to transfer information from short-term to long-term memory, and to utilize support in the form of multimodal presentation and selective reminding. Importantly, presentation of study materials in multiple modalities has been shown to facilitate learning and recall [26]. In the selective reminding procedure, the participant is selectively reminded of the objects not recalled on the previous trial. This permits simultaneous analysis of shortterm and long-term memory [27].

The main aims of the present study are to investigate episodic learning and memory functioning in the prodromal phase of HD, and whether the results vary as a function of time to clinical disease onset. Additionally, the study aims to examine if episodic learning and memory functioning is facilitated by multimodal encoding and/or cueing by means of selective reminding. The hypotheses are that memory deficits are most pronounced among those who are closest to clinical disease onset, and that memory deficits are attenuated by multimodal encoding and selective reminding. As a control, we investigate whether verbal episodic memory deficits can be identified by two different memory tasks; The Fuld Object Memory Evaluation (FOME; [23]) and Claeson-Dahl Learning Test [28].

\section{Method}

\subsection{Participants}

A predictive testing program for HD was introduced in 1990, and is an ongoing program at the Department of Clinical Genetics, Karolinska University Hospital, Stockholm, Sweden. All participants in the present study were recruited from the testing program and had applied for a predictive genetic test for HD. The testing procedure included drawing of a blood sample for genetic analysis. Linkage analysis was used for determination of genetic status until 1993, when the use of direct mutation analysis by determination of number of CAG repeats was established [1]. Participation in the study was voluntary and participants had to: 1) be 18 years of age or older; 2) have a $50 \%$ risk of HD or a $25 \%$ risk of HD if their parent with a 50\% risk of HD was deceased or participated in the program; 3) not have any neurological signs or symptoms severe enough to warrant a diagnosis of HD, as determined by neurological examination; 4) not have any comorbidity that causes major cognitive deficits; 5) not have current substance abuse; and 6) each time provide a written acknowledgement of participation. Experienced neurologists conducted neurological examinations in accordance with recommendations from Folstein et al. [29]. The neurologists were blind to the participants' genetic status. The majority of the participants did not know their genetic status at time of neuropsychological testing. Participants did not receive payment for participation. The recruitment of participants has previously been described in detail [see [30]].

Seventy individuals participated in the study. They were grouped according to their genetic status into HD mutation carriers (HD+; CAG repeats $\geq 36 ; n=32$ ) or noncarriers (HD-; CAG repeats $<36 ; n=38$ ) [2], herei- 
nafter named carriers and noncarriers. All but one of the carriers, who had taken the linkage analysis, proceeded with also taking the mutation analysis. This carrier developed symptoms of HD eight years after initial neuropsychological testing, which confirmed her carrier status.

A total of 12 carriers have been diagnosed with HD since the start of the program, providing the opportunity to determine how far from disease onset they were at the time of neuropsychological testing. For the remaining 20 mutation carriers, estimated age at onset was calculated using a regression equation described by Langbehn and associates [4] [31]. Predicted years to onset were calculated by subtracting current age from estimated age at onset. Years to onset was analyzed, using real years to onset when known, and predicted years for the remaining carriers, and found to be positively skewed (skewness $=1.455, S E=0.414$ ). Median split of the carrier group was performed into two groups using the median years to onset $(M d=12.49)$ : carriers with less than 12.5 years (range 0 - 12.33) to disease onset (HD+CLOSE; $n=16$ ); and carriers with 12.5 years or more (range 12.64 50.55) to disease onset (HD+DISTANT; $n=16$ ).

\subsection{Design and Procedure}

Three groups were compared to each other in a cross-sectional design: HD+CLOSE $(n=16)$, HD+DISTANT ( $n=16)$, and HD- $(n=38)$. Neuropsychological testing was carried out by experienced psychologists using a comprehensive test battery demanding 5 - 6 hours to administer (see [11] for details). Informed consent was obtained from the participants. All participants were tested individually and the tests were presented in the same order. To avoid fatigue, there were two breaks during the day, a 60-minute break after the first two hours of testing, and a 30-minute break after another 90 minutes. Claeson Dahl Verbal Learning Test was administered after the first break, and FOME after the second break. The study was approved by the Research Ethics Committee at the Karolinska Hospital and performed in accordance with the Helsinki Declaration.

\subsection{Cognitive Assessment}

The Fuld Object Memory Evaluation [FOME; [23]] was modified to include 16 objects, and administered using a selective reminding paradigm [27]. At presentation, the participants were asked to name 16 out-of-sight objects in a box using their hands for identification. After the naming by the participants, the psychologist visually showed and verbally named the objects. Most participants could name the objects by tactile inspection, and all participants confirmed the objects verbally after visual examination. As part of the standardized procedure, the participants were not informed about the memory task during presentation of the objects. After the multimodal presentation, objects were removed from sight and the participants were asked to verbally recall all objects. When the participants could not recall any further objects, or after a maximum of two minutes, the psychologist selectively reminded verbally of the objects not recalled, i.e. selective reminding. Immediately after the reminding, the participants were again asked to recall all 16 objects. There were a total of five recall trials, with selective reminding as necessary in each trial. The lag between two recall trials was 3 - 4 minutes, depending on how many objects were selectively reminded. Contrasting the initial recall trial with subsequent recall trials permits for analysis of multimodal presentation. The selective reminding paradigm allows also for the grouping of recalled items as emanating from short-term or long-term memory. If an item is recalled without selective reminding on the preceding trial, it is assumed to be retrieved from long-term memory [27].

\subsection{Indicators of Fuld Object Memory Evaluation}

According to Buschke [27] and Fuld [23] the following eight indicators are considered to capture memory performance:

1) Total recall (TR) is the sum of all recalled items on all trials. This is an indicator of encoding.

2) Long-term storage (LTS) is the sum of all cumulative items stored in long-term storage. An item is considered to be in long-term storage when it has been recalled two times or more in a row without reminding. LTS indexes storage and encoding into long-term storage.

3) Long-term retrieval (LTR) is the sum of all items retrieved from long-term memory (i.e. recalled two times in a row) on all trials. This is an indicator of retrieval.

4) List learning $(L L)$ is the sum of all items recalled on all consecutive trials. This is an index of both storage and retrieval. 
5) Random long-term retrieval ( $R L T R$ ) is the number of items inconsistently retrieved from long-term memory. This is calculated by subtracting LL from LTR, and is an index of retrieval failure.

6) Short-term recall (STR) is the sum of all items recalled from short-term storage, i.e. recalled after reminding on the previous trial. STR is an index of failure of transfer from short-term to long-term memory.

7) Percentage ineffective reminders is the percentage of reminders not resulting in recall of the item in the succeeding trial. It reflects encoding failure.

8) Total recall trial 1 is the number of items recalled on the first trial. This measures learning on trial 1, directly after multimodal presentation, and is thus a measure of attention and incidental memory.

The definitions of long-term storage, list learning, random long-term retrieval, and short-term recall have demonstrated good predictive validity [32]. Words consistently recalled from long-term memory (i.e. LL) are more likely to be recalled and/or recognized after a delay than words inconsistently recalled from long-term memory (i.e. RLTR) or words recalled from short-term memory.

The Claeson-Dahl Verbal Learning Test [28] was used as a measure of learning of unimodal, auditory, verbal stimuli. The participant was asked to remember 10 common Swedish words read at a pace of 2 seconds per word. After a 15 second delay, the participant was asked to recall all words. This procedure was repeated until the participant recalled all 10 words two trials in a row, or for a maximum of 10 trials. Indicators used were 1) number of words recalled on the first trial, which is a measure of learning of auditory, verbal stimuli, and 2) weighted points, which is a measure of total learning over all trials. For each trial the number of words recalled was subtracted from 10 and the difference multiplied by the number of the trial $(1,2,3$, etc.). These products were summed over all trials to produce the weighted points, where higher scores indicate worse performance.

\subsection{Statistical Analyses}

All statistical analyses were carried out using the Statistical Package for the Social Sciences (SPSS) version 22.0. Differences in demographic and genetic data were analyzed using Chi-square, Fisher's Exact Test, t-test, and Mann-Whitney's Test. Univariate Analysis of Variance (ANOVA) with group as independent variable and FOME indicators as dependent variables, and post-hoc Bonferroni adjusted follow-up t-tests were used to analyze group contrasts on the memory indicators. Bonferroni corrections were performed according to SPSS standard procedures; the original p-value is multiplied by number of comparisons (i.e. 3) to produce the reported p-value.

\section{Results}

\subsection{Demographic and Genetic Variables}

No statistically significant differences were found between the three groups in distribution of age, gender, or educational level. The HD+CLOSE group consumed more antidepressants than the HD- group. However, no significant differences were found between the groups on self-rated depression scores [Beck Depression Inventory; BDI; [33]]. Alcohol consumption was found to be non-normally distributed, and therefore analyzed using the Mann-Whitney Test. The participants in all groups consumed relatively small amounts of alcohol and tobacco, and no significant differences between the groups were detected (see Table 1).

The HD+DISTANT group had a higher proportion of fathers affected by the disease and shorter wildtype (i.e. non-mutated) HD allele than the HD- group. No other differences in genetic characteristics were found between the groups (see Table 2).

\subsection{Episodic Learning and Memory}

Descriptive and inferential statistics for the cognitive indicators are presented in detail in Table 3. For FOME, a statistically significant main effect of group was found for total recall $F(2,67)=5.434, p=0.007, \eta^{2}=0.140$. Subsequent group comparisons showed that the HD+CLOSE group recalled fewer items than the HD- group $p=0.014$. A main effect of group was also found for long-term storage $F(2,67)=5.637, p=0.005, \eta^{2}=0.144$, and the $\mathrm{HD}+\mathrm{CLOSE}$ and the HD+DISTANT groups were found to store fewer objects in long-term memory than the HD- group $p=0.020$ and $p=0.034$ respectively. For long-term retrieval, a main group effect was found $F(2,67)=$ 5.554, $p=0.006, \eta^{2}=0.142$, due to that the HD+CLOSE and the HD+DISTANT groups retrieved fewer items from long-term memory than the HD- group $p=0.016$ respective $p=0.049$. For list learning, a significant main 
Table 1. Characteristics of carriers close to disease onset $(<12.5$ years; HD+CLOSE), carriers distant from onset $(\geq 12.5$ years; HD+DISTANT), and noncarriers (HD-).

\begin{tabular}{|c|c|c|c|c|c|c|c|c|c|c|c|c|}
\hline & \multicolumn{3}{|c|}{$\begin{array}{c}\text { 1. HD+CLOSE } \\
(n=16)\end{array}$} & \multicolumn{3}{|c|}{$\begin{array}{l}\text { 2. HD+DISTANT } \\
(n=16)\end{array}$} & \multicolumn{3}{|c|}{$\begin{array}{l}\text { 3. } \mathrm{HD}^{-} \\
(n=38)\end{array}$} & \multicolumn{3}{|c|}{$\begin{array}{c}\text { Group comparisons } \\
p\end{array}$} \\
\hline & $\mathrm{n}$ & M & (SD) & $\mathrm{n}$ & M & (SD) & $\mathrm{n}$ & M & (SD) & $1-3$ & $2-3$ & $1-2$ \\
\hline $\mathrm{Age}^{\mathrm{a}}$ & & 37.7 & $(10.4)$ & & 32.4 & (7.4) & & 36.9 & $(10.1)$ & 0.769 & 0.114 & 0.106 \\
\hline Level of education (years) ${ }^{\mathrm{a}}$ & & 12.2 & $(2.4)$ & & 12.9 & (3.2) & & 12.8 & $(2.7)$ & 0.422 & 0.863 & 0.447 \\
\hline Beck Depression Inventory ${ }^{\mathrm{d}}$ & & 6.4 & (5.1) & & 6.6 & (6.3) & & 6.3 & $(9.1)$ & 0.971 & 0.925 & 0.944 \\
\hline \multicolumn{13}{|l|}{ Use of alcohol (per week) } \\
\hline Beer (cans) ${ }^{d}$ & & 1.5 & $(2.1)$ & & $1.3^{\mathrm{e}}$ & $(2.1)$ & & 0.9 & $(2.0)$ & 0.575 & 0.301 & 0.928 \\
\hline Wine (glasses) ${ }^{\mathrm{d}}$ & & 3.4 & $(8.0)$ & & $2.1^{\mathrm{e}}$ & (2.3) & & 1.9 & $(2.4)$ & 0.777 & 0.952 & 0.783 \\
\hline Spirits (centiliters) ${ }^{\mathrm{d}}$ & & 5.4 & (14.7) & & $0.0^{\mathrm{e}}$ & $(0.0)$ & & 0.5 & $(1.8)$ & 0.428 & 0.132 & 0.064 \\
\hline $\begin{array}{l}\text { Gender (Caucasian; } \\
\text { male/female) }\end{array}$ & $9 / 7$ & & & $8 / 8$ & & & $15 / 23$ & & & 0.359 & 0.352 & 0.982 \\
\hline \multicolumn{13}{|l|}{ Use of medications (persons) } \\
\hline Neuroleptics $^{c}$ & 0 & & & 0 & & & 0 & & & 1.000 & 1.000 & 1.000 \\
\hline Antidepressants ${ }^{\mathrm{c}}$ & 3 & & & 2 & & & 0 & & & $0.023^{*}$ & 0.084 & 1.000 \\
\hline Benzodiazepines $^{c}$ & 2 & & & 0 & & & 2 & & & 0.573 & 1.000 & 0.484 \\
\hline Asthma/allergy medications ${ }^{c}$ & 1 & & & 1 & & & 1 & & & 0.409 & 0.509 & 1.000 \\
\hline Diueretics/heart medications ${ }^{c}$ & 0 & & & 1 & & & 3 & & & 0.547 & 1.000 & 1.000 \\
\hline Other $^{c}$ & 6 & & & 2 & & & 13 & & & $0.817^{\mathrm{b}}$ & 0.182 & 0.220 \\
\hline \multicolumn{13}{|l|}{ Use of tobacco (persons) } \\
\hline Cigarettes $^{\mathrm{b}}$ & 5 & & & $5^{e}$ & & & 13 & & & 0.833 & 0.952 & $1.000^{\mathrm{c}}$ \\
\hline Snuff $^{\mathrm{c}}$ & 2 & & & $3^{\mathrm{e}}$ & & & 6 & & & 1.000 & 0.701 & 0.654 \\
\hline
\end{tabular}

${ }^{\mathrm{a}}$ Group comparisons performed using t-tests. ${ }^{\mathrm{b}}$ Chi-square. ${ }^{\mathrm{c}}$ Fisher's Exact Test. ${ }^{\mathrm{d}}$ Mann-Whitney's U-test. ${ }^{\mathrm{e}} \mathrm{n}=15$, one person's use of alcohol and tobacco not known. ${ }^{*} p<0.05$.

Table 2. Genetic characteristics of carriers close to disease onset ( $<12.5$ years; HD+CLOSE), carriers distant from onset ( $\geq 12.5$ years; $\mathrm{HD}+\mathrm{DISTANT}$ ), and noncarriers (HD-).

\begin{tabular}{|c|c|c|c|c|c|c|c|c|c|c|c|c|}
\hline & \multicolumn{3}{|c|}{$\begin{array}{l}\text { 1. HD+CLOSE } \\
(n=16)\end{array}$} & \multicolumn{3}{|c|}{$\begin{array}{l}\text { 2. HD+DISTANT } \\
(n=16)\end{array}$} & \multicolumn{3}{|c|}{$\begin{array}{l}\text { 3. HD- } \\
(n=38)\end{array}$} & \multicolumn{3}{|c|}{$\begin{array}{l}\text { Group comparisons } \\
P^{a}\end{array}$} \\
\hline & $n$ & $M$ & $S D$ & $n$ & $M$ & $S D$ & $n$ & $M$ & $S D$ & $1-3$ & $2-3$ & $1-2$ \\
\hline $\begin{array}{c}\text { Gender of affected parent } \\
\text { (male/female) }\end{array}$ & $8 / 8$ & $50 \%$ & & $11 / 5$ & & & $14 / 22^{c}$ & & & 0.454 & $0.047^{*}$ & 0.280 \\
\hline Age of onset of affected parent ${ }^{a}$ & & 43.4 & $(12.2)$ & & $49.3^{\mathrm{d}}$ & $(11.0)$ & & $47.0^{\mathrm{e}}$ & $(10.6)$ & 0.272 & 0.791 & 0.237 \\
\hline CAG length of wildtype allele ${ }^{a}$ & & $18.8^{\mathrm{t}}$ & $(2.0)$ & & 18.3 & $(3.2)$ & & $20.7^{\mathrm{g}}$ & (3.9) & 0.091 & $0.035^{*}$ & 0.577 \\
\hline CAG length of mutated allele ${ }^{a}$ & & 43.3 & $(2.4)$ & & 42.2 & (3.3) & & & & & & 0.273 \\
\hline Estimated years to onset ${ }^{\mathrm{a}, \mathrm{h}}$ & & 6.5 & $(4.1)$ & & 22.3 & $(10.7)$ & & & & & & $<0.001^{* * *}$ \\
\hline
\end{tabular}

${ }^{\mathrm{a}}$ Group comparisons performed using t-tests. ${ }^{\mathrm{b}}$ Group comparisons performed using Chi-2. Percentage indicates proportion of participants with an affected father in respective group. ${ }^{c} n=36 .{ }^{d} n=14 .{ }^{e} n=30 .{ }^{f} n=15$. ${ }^{g}$ The longer of the two wildtype alleles reported. ${ }^{h}$ Calculated from Langbehn et al. [4] [31]. ${ }^{*} p<0.05,{ }^{* *} p<0.01,{ }^{* * * *} p<0.001$.

effect of group $F(2,67)=4.941, p=0.010, \eta^{2}=0.129$, was due to that the HD- group outperformed the HD+ CLOSE group $p=0.016$. Short-term recall showed also a main effect of group $F(2,67)=4.855, p=0.011, \eta^{2}=$ 0.127, with the HD+CLOSE and HD+DISTANT groups recalling more items from short-term storage than the HD- group both $p$ 's $=0.044$. For percentage ineffective reminders, there was a significant main effect of group $F(2,67)=3.911, p=0.025, \eta^{2}=0.105$, due to the HD+CLOSE group utilizing reminders less effectively than the HD- group $p=0.023$. No main effect of group was found for random long-term retrieval $F(2,67)=2.099, p$ $=0.131, \eta^{2}=0.059$. Analyzing number of words recalled at the first trial also revealed no main effect of group 
Table 3. Group comparisons carriers close to disease onset (HD+CLOSE), carriers distant from onset (HD+DISTANT), and noncarriers (HD-) on indicators of episodic memory, with significance levels and effect sizes for each contrast.

\begin{tabular}{|c|c|c|c|c|c|c|c|c|c|c|c|c|}
\hline & \multicolumn{2}{|c|}{$\begin{array}{c}\text { 1. HD+CLOSE } \\
(\mathrm{n}=16)\end{array}$} & \multicolumn{2}{|c|}{$\begin{array}{c}2 . \\
\text { HD+DISTANT } \\
(\mathrm{n}=16)\end{array}$} & \multicolumn{2}{|c|}{$\begin{array}{l}\text { 3. HD- } \\
(\mathrm{n}=38)\end{array}$} & \multicolumn{6}{|c|}{$\begin{array}{l}\text { Group comparisons } \\
\qquad\left(P^{\mathrm{a}}\right)\end{array}$} \\
\hline & $M$ & $(S D)$ & $M$ & $(S D)$ & $M$ & $(S D)$ & & $\begin{array}{l}-3 \\
\left.d^{b}\right)\end{array}$ & & $\begin{array}{l}-3) \\
\left.d^{b}\right)\end{array}$ & & $\begin{array}{l}-2 \\
\left.d^{b}\right)\end{array}$ \\
\hline \multicolumn{13}{|l|}{$\begin{array}{c}\text { Fuld Object } \\
\text { Memory Evaluation }\end{array}$} \\
\hline Total Recall & 63.7 & $(7.2)$ & 65.0 & (9.6) & 69.8 & (5.4) & $0.014^{*}$ & $(-1.02)$ & 0.073 & $(-0.70)$ & 1.000 & $(-0.15)$ \\
\hline Long-Term Storage & 61.9 & $(8.4)$ & 62.4 & (12.3) & 68.9 & (6.4) & $0.020^{*}$ & $(-0.99)$ & $0.034^{*}$ & $(-0.76)$ & 1.000 & $(-0.05)$ \\
\hline Long-Term Retrieval & 57.3 & $(10.6)$ & 58.6 & $(14.0)$ & 66.2 & $(8.2)$ & $0.016^{*}$ & $(-0.99)$ & $0.049^{*}$ & $(-0.74)$ & 1.000 & $(-0.10)$ \\
\hline List Learning & 49.3 & $(14.3)$ & 52.8 & $(16.8)$ & 61.2 & $(12.2)$ & $0.016^{*}$ & $(-0.93)$ & 0.146 & $(-0.61)$ & 1.000 & $(-0.23)$ \\
\hline Short-Term Recall & 6.3 & (3.9) & 6.3 & $(4.8)$ & 3.4 & $(3.2)$ & $0.044^{*}$ & $(0.85)$ & $0.044^{*}$ & $(0.78)$ & 1.000 & $(0.0)$ \\
\hline Ineffective reminders \% & 16.0 & $(13.8)$ & 11.3 & $(12.4)$ & 6.7 & (8.9) & $0.023^{*}$ & $(0.88)$ & 0.587 & $(0.46)$ & 0.685 & $(0.36)$ \\
\hline $\begin{array}{c}\text { Random Long-Term } \\
\text { Retrieval }\end{array}$ & 8.2 & $(4.9)$ & 5.8 & $(4.5)$ & 5.2 & (5.1) & 0.138 & $(0.59)$ & 1.000 & $(0.12)$ & 0.495 & $(0.51)$ \\
\hline Trial 1 Recall & 10.4 & $(2.0)$ & 10.6 & $(2.5)$ & 11.4 & (1.9) & 0.316 & $(-0.52)$ & 0.554 & $(-0.38)$ & 1.000 & $(-0.09)$ \\
\hline \multicolumn{13}{|l|}{$\begin{array}{l}\text { Claeson-Dahl } \\
\text { Learning Test }\end{array}$} \\
\hline Trial 1 Recall & 4.3 & (1.3) & 4.5 & (1.4) & 5.6 & $(1.0)$ & $<0.001^{*}$ & $(-1.19)$ & $0.005^{*}$ & $(-0.97)$ & 1.000 & $(-0.15)$ \\
\hline Weighted Points & 123.1 & ((90.9) & 90.4 & (93.8) & 56.8 & (59.1) & $0.014^{*}$ & $(0.95)$ & 0.425 & $(0.47)$ & 0.678 & $(0.35)$ \\
\hline
\end{tabular}

${ }^{\mathrm{a}}$ Group comparisons performed using Bonferroni adjustment (the original $p$-value is multiplied by number of comparisons, i.e. 3 , to produce the re-

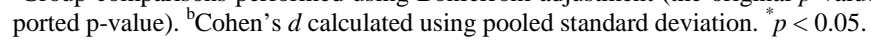

$F(2,67)=1.749, p=0.182, \eta^{2}=0.050$.

For the Claeson-Dahl Learning Test, the number of words recalled at the first trial revealed a main effect of group $F(2,67)=10.414, p<0.001, \eta^{2}=0.237$. The HD- group recalled more words than the HD+CLOSE $p<$ 0.001 and HD+DISTANT $p=0.005$ groups. No significant difference was found between the HD+CLOSE and HD+DISTANT groups. For Claeson-Dahl Weighted Points, there was a significant main effect of group $F(2,67)=$ 4.523, $p=0.014, \eta^{2}=0.119$, the HD+CLOSE group receiving a higher score than the HD- group $p=0.014$.

\section{Discussion}

The main purpose of this study was to investigate episodic memory functioning in prodromal HD, and whether memory deficits, if any, vary as a function of proximity to clinical diagnosis. The HD+CLOSE group scored lower compared to the noncarriers on FOME measures of total recall, long-term storage, long-term retrieval, list learning, and utilization of reminders at presentation. In addition, the HD+DISTANT group scored lower than the noncarriers on FOME measures of long-term storage and retrieval. Both carrier groups resorted to recall from short-term memory to a greater extent (FOME), and had lower performance on Claeson-Dahl measures of recall on first trial and higher weighted points. However, no significant differences were found between the HD+CLOSE and the HD+DISTANT groups.

The HD+CLOSE group recalled fewer words summed over the five FOME trials than the HD- group. This suggests that carriers close to disease onset suffer overall deficient learning. In addition, both carrier groups encoded fewer items in long-term storage than the HD- group, implicating learning deficits. Furthermore, both carrier groups retrieved fewer items from long-term storage than the HD- group, implicating deficits in retrieval. Also, the HD+CLOSE group performed lower than the HD- group on list learning. List learning is a measure of retrieval on consecutive trials, and thus a measure of consistent retrieval from long-term memory. Earlier research using the selective reminding procedure has shown deficits in long-term retrieval in manifest HD [34], and our current study extends this finding into the prodromal phase of HD. Our findings indicate deficient learning and inconsistent retrieval. This is in line with common characterization of memory problems in manif- 
est HD [22] [35]-[37] and prodromal HD [14] as emanating from disrupted encoding and retrieval.

Multimodal encoding has been shown to facilitate recall in the normal population and to attenuate differences in recall between young and elderly [26] [38]. Interestingly, in contrast to the overall results, no significant differences were detected between the carriers and noncarriers on number of words recalled at the FOME first trial where stimuli are presented in tactile, visual, and auditory modalities just before the recall. On the contrary, the prodromal HD+ groups recalled fewer words than the HD- group on Claeson-Dahl first trial, where only auditory stimuli are presented. This suggests that multimodal encoding has positive effects attenuating the difference in recall between carriers and noncarriers. The HD+CLOSE group recalled fewer objects in total than the HDgroup on the FOME trials using selective reminding and overall fewer words on Claeson-Dahl. Thus, our results suggest that in the prodromal phase of HD, multimodal encoding attenuates differences, but verbal cueing in the form of selective reminding does not. This finding may be used in clinical settings such that it is beneficial to give information in multiple modalities instead of relying on only verbal information, even with repeated presentations.

The presentation scheme in FOME, which guarantees processing of the objects, should maximize attention to information to be remembered and minimize confounds from attentional disturbances. This supportive type of presentation can be seen as the reason for the lack of performance differences between the carriers and the noncarriers on the first FOME recall trial. As subsequent presentations are verbal only, it cannot be ruled out that impaired attention causes the memory deficits seen in subsequent trials. To test this hypothesis, experimental inclusion of, for example, conditions with divided attention are required.

The HD+DISTANT and HD+CLOSE groups were found to utilize short-term recall to a greater extent than the HD- group. Short-term recall is a measure of being able to recall an item only once after being reminded, hence the information has not been transferred to long-term memory. This suggests that carriers had more difficulties than noncarriers in transferring information from short-term to long-term memory. Furthermore, the results also showed that the HD+CLOSE group, but not the HD+DISTANT group, was deficient in utilization of selective reminding, suggesting deficits in short-term memory. Short-term memory is important for the acquisition of information, and for the transfer of information to long-term memory [39]. The found dissociation suggests that the transfer of information from short-term to long-term memory may be an early deficit in episodic memory in the prodromal phase of HD, and that the utilization of reminders is deficient later in the prodromal phase. Indeed, the HD+CLOSE group utilized reminders less effectively than the HD- group, indicating that the HD+CLOSE group did not benefit as much from supportive verbal feedback for learning as the noncarriers. This was confirmed both by FOME and Claeson-Dahl Verbal Learning Test.

Slower processing speed may explain the lower memory performance of the carrier groups, but since initial presentation in FOME is done at a rate chosen by the participant, this should be less of a problem than in tests where presentation time is fixed (e.g. most verbal learning tests). Furthermore, longer presentation time has been found to facilitate recall in both young and elderly subjects [40]. As a caveat, the extent to which the positive effects of multimodal encoding in FOME were also speed related effects, remains unknown.

Prodromal HD is associated with progressive reduction in striatal volume [9] [41]-[43], frontal lobe atrophy [44]-[47], and dysfunction of fronto-striatal circuits [48] [49]. Our findings are consistent with damage to fronto-striatal circuitry being associated with disruption of episodic memory encoding and retrieval [14] [44] [49][51].

The median cut-off point of 12.5 years used for grouping carriers into close to onset or distant from onset corresponds well with other studies which have detected markers of the disease process in cognitive functioning 9 - 15 years before clinical diagnosis [12] [52]. Such early markers include verbal episodic memory [9] [11][13], verbal fluency [8] [12] [53], executive function [11] [12] [53], and processing speed [10]-[13] [53]. Our study adds to such findings, first by detecting episodic recall deficits in the same prodromal range, second by indicating specific functions affected, and third by detecting deficits in short-term memory (i.e. ineffective reminders) only in the HD+CLOSE and in transfer to long-term memory (i.e. short-term recall) in both carrier groups.

The inclusion of the Claeson-Dahl Learning Test results complement the FOME results. First, by showing that when unimodal (verbal) presentation is used, negative differences appear at immediate recall for both HD+ groups. Second, by showing that the HD+CLOSE group performed worse (a higher weighted score) than the HD- group across trials with repeated verbal presentation of all items.

A limitation of the present study is its relatively small sample size. However, we detected rather large mean 
differences on our outcome measures, which in turn provided good statistical power. No significant differences were found between the HD+CLOSE and the HD+DISTANT group. This may indicate a problem with our grouping scheme. However, as noted above, the median cut-off point corresponds well with other studies. The lack of significance in age differences between the HD+CLOSE and HD+DISTANT groups may be due to the small sample size, since the numerical values indicate a five year age difference. However, including age as a covariate in the analyses did not alter the overall pattern of results, why we excluded age in the final analyses. The present study had a cross-sectional design, and the finding that episodic memory declines as a function of time to disease onset needs to be confirmed by larger samples utilizing a longitudinal design. The measures of long-term storage and retrieval used in this study were indirect, as no delayed recognition or recall trials were administered. However, there is evidence that the FOME indicators are valid as measures of long-term storage and retrieval [32] [54].

The HD+CLOSE group included more participants that used antidepressants than the HD- group. However, follow-up comparisons between the antidepressant users and non-users in the HD+CLOSE group revealed no significant differences in any of the outcome measures (results not shown). This suggests that use of antidepressants did not have any major contribution to the deficits found in the HD+CLOSE group. Additionally, modern antidepressants do not substantially affect cognitive function [55]. Further, only a few of the participants used medications such as benzodiazepines, known to affect cognition, and the use was equally distributed across the three groups. The distribution of other variables, such as depression and alcohol usage, were found not to differ between groups, which strengthens our conclusions that prodromal HD is associated with deficits in episodic memory.

Our finding that the HD+DISTANT group, compared to the HD- group, had shorter wildtype alleles (all in the normal range) and a higher proportion of fathers affected by HD is noteworthy. Paternal transmission has been linked to an increase in number of CAG repeats in the HD gene and is also associated with earlier disease onset [56]. However, neither paternal transmission, nor alleles in the normal range are known to have affected cognitive function, hence these differences are not likely to affect the results in this study.

\section{Conclusion}

In conclusion, deficits found in episodic learning and memory were most pronounced in carriers less than 12.5 years before the onset of Huntington's disease. This suggests that underlying disease processes contribute to deficient learning and inconsistent retrieval, and that the deficits extend to selective reminding. Multimodal presentation, on the other hand, may facilitate learning and memory in prodromal HD. Furthermore, these findings are consistent with dysfunction and atrophy in striatum, frontal lobes, fronto-striatal circuits, and hippocampus. The results also suggest that impaired transfer from short-term memory to long-term memory may be an earlier marker of disease progression than impaired short-term memory. This confirms results from earlier studies that indicate deficits in episodic memory functioning more than a decade before manifest disease onset [35] [48]. Importantly, the memory deficits found in this study should be interpreted as signs of early disease progression rather than proper clinical symptoms. The current study contributes to the growing understanding that cognitive function is deficient in prodromal $\mathrm{HD}$ at least one decade before the onset of motor symptoms.

\section{Acknowledgements}

The authors thank the Department of Clinical Genetics, Karolinska University Hospital for assistance and all participants who generously gave their time to this project.The research was supported by grants from The Association of Neurologically Disabled Persons, Stockholm County Council, PickUp, and the Swedish Research Council to Tarja-Brita Robins Wahlin. The authors wish to thank Maria U. Larsson and Andreas Frick for their contribution towards data collection assessments over the years.

\section{References}

[1] Huntington's Disease Collaborative Research Group (1993) A Novel Gene Containing a Trinucleotide Repeat That Is Expanded and Unstable on Huntington's Disease Chromosomes. Cell, 72, 971-983. http://dx.doi.org/10.1016/0092-8674(93)90585-E

[2] Rubinsztein, D.C., Leggo, J., Coles, R., Almqvist, E., Biancalana, V., Cassiman, J.J., Chotai, K., Connarty, M., Crau- 
ford, D., Curtis, A., Curtis, D., Davidson, M.J., Differ, A.M., Dode, C., Dodge, A., Frontali, M., Ranen, N.G., Stine, O.C., Sherr, M., Abbott, M.H., Franz, M.L., Graham, C.A., Harper, P.S., Hedreen, J.C. and Hayden, M.R. (1996) Phenotypic Characterization of Individuals with 30-40 CAG Repeats in the Huntington Disease (HD) Gene Reveals HD Cases with 36 Repeats and Apparently Normal Elderly Individuals with 36-39 Repeats. American Journal of Human Genetics, 59, 16-22.

[3] Bates, G., Harper, P.S. and Jones, L. (2002) Huntington’s Disease. 3rd Edition, Oxford University Press, Oxford.

[4] Langbehn, D.R., Brinkman, R.R., Falush, D., Paulsen, J.S. and Hayden, M.R. (2004) A New Model for Prediction of the Age of Onset and Penetrance for Huntington's Disease Based on CAG Length. Clinical Genetics, 65, 267-277. http://10.1111/j.1399-0004.2004.00241.x

[5] Roos, R.A., Vegter-van der Vlis, M., Hermans, J., Elshove, H.M., Moll, A.C., van de Kamp, J.J. and Bruyn, G.W. (1991) Age at Onset in Huntington's Disease: Effect of Line of Inheritance and Patient's Sex. Journal of Medical Genetics, 28, 515-519. http://jmg.bmj.com http://dx.doi.org/10.1136/jmg.28.8.515

[6] Gusella, J.F., Wexler, N.S., Conneally, P.M., Naylor, S.L., Anderson, M.A., Tanzi, R.E., Watkins, P.C., Ottina, K., Wallace, M.R., Sakaguchi, A.Y., Young, A.B., Shoulson, I., Bonilla, E. and Martin, J.B. (1983) A Polymorphic DNA Marker Genetically Linked to Huntington’s Disease. Nature, 306, 234-238. http://dx.doi.org/10.1038/306234a0

[7] Brandt, J., Shpritz, B., Codori, A.-M., Margolis, R. and Rosenblatt, A. (2002) Neuropsychological Manifestations of the Genetic Mutation for Huntington's Disease in Presymptomatic Individuals. Journal of the International Neuropsychological Society, 8, 918-924. http://dx.doi.org/10.1017/S1355617702870060

[8] Larsson, M.U., Almkvist, O., Luszcz, M.A. and Robins Wahlin, T.-B. (2008) Phonemic Fluency Deficits in Asymptomatic Gene Carriers for Huntington’s Disease. Neuropsychology, 22, 596-605. http://dx.doi.org/10.1037/0894-4105.22.5.596

[9] Paulsen, J.S., Langbehn, D.R., Stout, J.C., Aylward, E., Ross, C.A., Nance, M., Guttman, M., Johnson, S., MacDonald, M., Beglinger, L.J., Duff, K., Kayson, E., Biglan, K., Shoulson, I., Oakes, D. and Hayden, M. (2008) Detection of Huntington's Disease Decades before Diagnosis: The Predict-HD Study. Journal of Neurology, Neurosurgery, and Psychiatry, 79, 874-880. http://dx.doi.org/10.1136/jnnp.2007.128728

[10] Robins Wahlin, T.-B., Larsson, M. and Luszcz, M. (2010) WAIS-R Features of Preclinical Huntington’s Disease: Implications for Early Detection. Dementia and Geriatric Cognitive Disorders, 29, 342-350. http://dx.doi.org/10.1159/000288775

[11] Robins Wahlin, T.-B., Lundin, A. and Dear, K. (2007) Early Cognitive Deficits in Swedish Gene Carriers of Huntington's Disease. Neuropsychology, 21, 31-44. http://dx.doi.org/10.1037/0894-4105.21.1.31

[12] Stout, J.C., Paulsen, J.S., Queller, S., Solomon, A.C., Whitlock, K.B., Campbell, J.C., Carlozzi, N., Duff, K., Beglinger, L.J., Langbehn, D.R., Johnson, S.A., Biglan, K.M. and Aylward, E.H. (2011) Neurocognitive Signs in Prodromal Huntington Disease. Neuropsychology, 25, 1-14. http://dx.doi.org/10.1037/a0020937

http://www.ncbi.nlm.nih.gov/pmc/articles/PMC3017660/pdf/nihms224607.pdf

[13] Harrington, D.L., Smith, M.M., Zhang, Y., Carlozzi, N.E. and Paulsen, J.S. (2012) Cognitive Domains That Predict Time to Diagnosis in Prodromal Huntington Disease. Journal of Neurology, Neurosurgery and Psychiatry, 83, 612-619. http://jnnp.bmj.com/content/83/6/612.full.pdf http://dx.doi.org/10.1136/jnnp-2011-301732

[14] Solomon, A.C., Stout, J.C., Johnson, S.A., Langbehn, D.R., Aylward, E.H., Brandt, J., Ross, C.A., Beglinger, L., Hayden, M.R., Kieburtz, K., Kayson, E., Julian-Baros, E., Duff, K., Guttman, M., Nance, M., Oakes, D., Shoulson, I., Penziner, E. and Paulsen, J.S. (2007) Verbal Episodic Memory Declines Prior to Diagnosis in Huntington's Disease. Neuropsychologia, 45, 1767-1776. http://dx.doi.org/10.1016/j.neuropsychologia.2006.12.015

[15] Butters, N., Sax, D., Montgomery, K. and Tarlow, S. (1978) Comparison of the Neuropsychological Deficits Associated with Early and Advanced Huntington's Disease. Archives of Neurology, 35, 585-589. http://search.ebscohost.com/login.aspx?direct=true\&db=cmedm\&AN=150836\&site=ehost-live http://dx.doi.org/10.1001/archneur.1978.00500330033006

[16] Montoya, A., Pelletier, M., Menear, M., Duplessis, E., Richer, F. and Lepage, M. (2006) Episodic Memory Impairment in Huntington's Disease: A Meta-Analysis. Neuropsychologia, 44, 1984-1994. http://dx.doi.org/10.1016/j.neuropsychologia.2006.01.015

[17] Caine, E.D., Hunt, R.D., Weingartner, H. and Ebert, M.H. (1978) Huntington’s Dementia. Clinical and Neuropsychological Features. Archives of General Psychiatry, 35, 377-384. http://dx.doi.org/10.1001/archpsyc.1978.01770270127013

[18] Beglinger, L.J., O’Rourke, J.J., Wang, C., Langbehn, D.R., Duff, K. and Paulsen, J.S. (2010) Earliest Functional Declines in Huntington Disease. Psychiatry Research, 178, 414-418. http://dx.doi.org/10.1016/j.psychres.2010.04.030 http://ac.els-cdn.com/S0165178110001897/1-s2.0-S0165178110001897-main.pdf? tid=15748d52-cf18-11e4-89b8-00 
$\underline{\text { 000aab0f02\&acdnat }=1426866487 \_8 f 95 e 4 d 5 d 9 b 7 c 9 e 335 b d c 65 b c 9 e b b c f e}$

[19] Dorsey, E.R., Beck, C.A., Darwin, K., Nichols, P., Brocht, A.F., Biglan, K.M. and Shoulson, I. (2013) Natural History of Huntington Disease. JAMA Neurology, 70, 1520-1530.

http://archneur.jamanetwork.com/data/Journals/NEUR/929441/noi130064.pdf

[20] Williams, J.K., Hamilton, R., Nehl, C., McGonigal-Kenney, M., Schutte, D.L., Sparbel, K., Birrer, E., Tripp-Reimer, T., Friedrich, R., Penziner, E., Jarmon, L. and Paulsen, J. (2007) No One Else Sees the Difference: "Family Members" Perceptions of Changes in Persons with Preclinical Huntington Disease. American Journal of Medical Genetics B Neuropsychiatric Genetics, 144, 636-641. http://dx.doi.org/10.1002/ajmg.b.30479

[21] Zakzanis, K.K. (1998) The Subcortical Dementia of Huntington's Disease. Journal of Clinical and Experimental Neuropsychology, 20, 565-578. http://dx.doi.org/10.1076/jcen.20.4.565.1468

[22] Pillon, B., Deweer, B., Agid, Y. and Dubois, B. (1993) Explicit Memory in Alzheimer’s, Huntington's, and Parkinson's Diseases. Archives of Neurology, 50, 374-379. http://dx.doi.org/10.1001/archneur.1993.00540040036010

[23] Fuld, P.A. (1980) Guaranteed Stimulus-Processing in the Evaluation of Memory and Learning. Cortex, 16, $255-271$. http://dx.doi.org/10.1016/S0010-9452(80)80061-X

[24] Hill, R.D., Neely, A.S. and Backman, L. (1997) Predictors of Change on the Fuld Object Memory Evaluation in a Two-Year Longitudinal Study of Optimally Healthy Very Old Adults. Aging and Mental Health, 1, 140-148. http://dx.doi.org/10.1080/13607869757236

[25] Wall, J.R., Deshpande, S.A., MacNei, S.E. and Lichtenberg, P.A. (1998) The Fuld Object Memory Evaluation, a Useful Tool in the Assessment of Urban Geriatric Patients. Clinical Gerontologist, 19, 39-49. http://dx.doi.org/10.1300/J018v19n01_04

[26] Mastroberardino, S., Santangelo, V., Botta, F., Marucci, F. and Olivetti Belardinelli, M. (2008) Guaranteed Stimulus-Processing in the Evaluation of Memory and Learning. Cognitive Processing, 9, 69-76. http://dx.doi.org/10.1007/s10339-007-0195-6

[27] Buschke, H. (1973) Selective Reminding for Analysis of Memory and Learning. Journal of Verbal Learning and Verbal Behavior, 12, 543-550. http://dx.doi.org/10.1016/S0022-5371(73)80034-9

[28] Claeson, L.E., Esbjörnsson, E., Carlé, B.M. and Wahlbin, M. (1971) Claeson-Dahls inlärningstest för kliniskt bruk (Claeson-Dahl's Learning Test). Psykologiförlaget AB, Stockholm.

[29] Folstein, S.E., Jensen, B., Leigh, R.J. and Folstein, M.F. (1983) The Measurement of Abnormal Movement: Methods Developed for Huntington's Disease. Neurobehavioral Toxicology and Teratology, 5, 605-609.

[30] Robins Wahlin, T.-B., Bäckman, L., Lundin, A., Haegermark, A., Winblad, B. and Anvret, M. (2000) High Suicidal Ideation in Persons Testing for Huntington's Disease. Acta Neurologica Scandinavica, 102, 150-161. http://dx.doi.org/10.1034/j.1600-0404.2000.102003150.x

[31] Langbehn, D.R., Hayden, M.R. and Paulsen, J.S. (2010) CAG-Repeat Length and the Age of Onset in Huntington Disease (HD): A Review and Validation Study of Statistical Approaches. American Journal of Medical Genetics Part B: Neuropsychiatric Genetics, 9999B, 397-408. http://dx.doi.org/10.1002/ajmg.b.30992

[32] Lezak, M.D., Howieson, D.B. and Loring, D.W. (2004) Neuropsychological Assessment. 4th Edition, Oxford University Press, New York.

[33] Beck, A.T., Ward, C.H., Mendelson, M., Mock, J. and Erbaugh, J. (1961) An Inventory for Measuring Depression. Archives of General Psychiatry, 4, 561-571. http://dx.doi.org/10.1001/archpsyc.1961.01710120031004

[34] Paulsen, J.S., Salmon, D.P., Monsch, A.U., Butters, N., Swenson, M.R. and Bondi, M.W. (1995) Discrimination of Cortical from Subcortical Dementias on the Basis of Memory and Problem-Solving Tests. Journal of Clinical Psychology, 51, 48-58. http://dx.doi.org/10.1002/1097-4679(199501)51:1<48::AID-JCLP2270510109>3.0.CO;2-E

[35] Butters, N., Wolfe, J., Martone, M., Granholm, E. and Cermak, L.S. (1985) Memory Disorders Associated with Huntington's Disease: Verbal Recall, Verbal Recognition and Procedural Memory. Neuropsychologia, 23, 729-743. http://dx.doi.org/10.1016/0028-3932(85)90080-6

[36] Lundervold, A.J. (1994) Characteristic Pattern of Verbal Memory Function in Patients with Huntington’s Disease. Scandinavian Journal of Psychology, 35, 38-47. http://dx.doi.org/10.1111/j.1467-9450.1994.tb00931.x

[37] Perry, R.J. and Hodges, J.R. (1996) Spectrum of Memory Dysfunction in Degenerative Disease. Current Opinion in Neurology, 9, 281-285. http://dx.doi.org/10.1097/00019052-199608000-00007

[38] Bäckman, L. and Nilsson, L. (1985) Prerequisites for Lack of Age Differences in Memory Performance. Experimental Aging Research, 11, 67-73. http://dx.doi.org/10.1080/03610738508259282

[39] Baddeley, A. (2003) Working Memory: Looking Back and Looking Forward. Nature Reviews Neuroscience, 4, 829839. http://dx.doi.org/10.1038/nrn1201

[40] Weible, J., Nuest, B., Welty, J., Pate, W. and Turner, M. (2002) Demonstrating the Effects of Presentation Rate on 
Aging Memory Using the California Verbal Learning Test (CVLT). Aging, Neuropsychology, and Cognition (Neuropsychology, Development and Cognition), 9, 38-47. http://dx.doi.org/10.1076/anec.9.1.38.834

[41] Aylward, E.H., Sparks, B.F., Field, K.M., Yallapragada, V., Shpritz, B.D., Rosenblatt, A., Brandt, J., Gourley, L.M., Liang, K., Zhou, H., Margolis, R.L. and Ross, C.A. (2004) Onset and Rate of Striatal Atrophy in Preclinical Huntington Disease. Neurology, 63, 66-72. http://dx.doi.org/10.1212/01.WNL.0000132965.14653.D1

[42] Bonner-Jackson, A., Long, J.D., Westervelt, H., Tremont, G., Aylward, E. and Paulsen, J.S. (2013) Cognitive Reserve and Brain Reserve in Prodromal Huntington’s Disease. Journal of the International Neuropsychological Society, 19, 739-750. http://dx.doi.org/10.1017/S1355617713000507 http://journals.cambridge.org/download.php?file=\%2FINS\%2FINS19_07\%2FS1355617713000507a.pdf\&code=0a2cc df33aa4a88250aadfcbedad50cd

[43] Aylward, E.H., Harrington, D.L., Mills, J.A., Nopoulos, P.C., Ross, C.A., Long, J.D., Liu, D., Westervelt, H.K. and Paulsen, J.S. (2013) Regional Atrophy Associated with Cognitive and Motor Function in Prodromal Huntington Disease. Journal of Huntingtons Disease, 2, 477-489.

http://www.ncbi.nlm.nih.gov/pmc/articles/PMC4412155/pdf/nihms640985.pdf

[44] Montoya, A., Price, B.H., Menear, M. and Lepage, M. (2006) Brain Imaging and Cognitive Dysfunctions in Huntington's Disease. Journal of Psychiatry \& Neuroscience, 31, 21-29. Copyright 2015, 8872147 Canada Inc.

[45] Paulsen, J.S. (2009) Functional Imaging in Huntington’s Disease. Experimental Neurology, 216, 272-277. http://www.sciencedirect.com/science/article/B6WFG-4V94X1C-1/2/46f187d39554216f33bec0cc0f9d2d04 http://dx.doi.org/10.1016/j.expneurol.2008.12.015

[46] Rosas, H.D., Hevelone, N.D., Zaleta, A.K., Greve, D.N., Salat, D.H. and Fischl, B. (2005) Regional Cortical Thinning in Preclinical Huntington Disease and Its Relationship to Cognition. Neurology, 65, 745-747. http://dx.doi.org/10.1212/01.wnl.0000174432.87383.87

[47] Wolf, R.C., Vasic, N., Schonfeldt-Lecuona, C., Landwehrmeyer, G.B. and Ecker, D. (2007) Dorsolateral Prefrontal Cortex Dysfunction in Presymptomatic Huntington’s Disease: Evidence from Event-Related fMRI. Brain, 130, 2845. http://dx.doi.org/10.1093/brain/awm210

[48] Wolf, R.C., Sambataro, F., Vasic, N., Schönfeldt-Lecuona, C., Ecker, D. and Landwehrmeyer, B. (2008) Aberrant Connectivity of Lateral Prefrontal Networks in Presymptomatic Huntington's Disease. Experimental Neurology, 213, 137-144. http://dx.doi.org/10.1016/j.expneurol.2008.05.017

[49] Wolf, R.C., Thomann, P.A., Thomann, A.K., Vasic, N., Wolf, N.D., Landwehrmeyer, G.B. and Orth, M. (2013) Brain Structure in Preclinical Huntington's Disease: A Multi-Method Approach. Neuro-Degenerative Diseases, 12, 13-22. http://www.karger.com/Article/Pdf/338635 http://dx.doi.org/10.1159/000338635

[50] Wolf, R.C., Sambataro, F., Vasic, N., Wolf, N.D., Thomann, P.A., Landwehrmeyer, G.B. and Orth, M. (2014) Longitudinal Task-Negative Network Analyses in Preclinical Huntington's Disease. European Archives of Psychiatry and Clinical Neuroscience, 264, 493-505. http://www.ncbi.nlm.nih.gov/pubmed/24071913 http://dx.doi.org/10.1007/s00406-013-0447-7

[51] Dogan, I., Eickhoff, S.B., Schulz, J.B., Shah, N.J., Laird, A.R., Fox, P.T. and Reetz, K. (2013) Consistent Neurodegeneration and Its Association with Clinical Progression in Huntington's Disease: A Coordinate-Based Meta-Analysis. Neuro-Degenerative Diseases, 12, 23-35. http://www.karger.com/Article/Pdf/339528 http://dx.doi.org/10.1159/000339528

[52] Paulsen, J.S., Long, J.D., Johnson, H.J., Aylward, E.H., Ross, C.A., Williams, J.K., Nance, M.A., Erwin, C.J., Westervelt, H.J., Harrington, D.L., Bockholt, H.J., Zhang, Y., McCusker, E.A., Chiu, E.M. and Panegyres, P.K. (2014) Clinical and Biomarker Changes in Premanifest Huntington Disease Show Trial Feasibility: A Decade of the PREDICT-HD Study. Frontiers in Aging Neuroscience, 6, 78.

http://www.ncbi.nlm.nih.gov/pmc/articles/PMC4000999/pdf/fnagi-06-00078.pdf http://dx.doi.org/10.3389/fnagi.2014.00078

[53] Robins Wahlin, T.-B. and Byrne, G.J. (2012) Cognition in Huntington’s Disease. In: Tunali, N.E., Ed., Huntington’s Disease-Core Concepts and Current Advances, InTech, Rijeka, 175-200. http://www.intechopen.com/articles/show/title/cognition-in-huntington-s-disease

[54] Beatty, W.W., Krull, K.R., Wilbanks, S.L., Blanco, C.R., Hames, K.A. and Paul, R.H. (1996) Further Validation of Constructs from the Selective Reminding Test. Journal of Clinical and Experimental Neuropsychology, 18, 52-55. http://dx.doi.org/10.1080/01688639608408261

[55] Biringer, E., Rongve, A. and Lund, A. (2009) A Review of Modern Antidepressants Effects on Neurocognitive Function. Current Psychiatry Reviews, 5, 164-174. http://dx.doi.org/10.2174/157340009788971137

[56] Kremer, B., Almqvist, E., Theilmann, J., Spence, N., Telenius, H., Goldberg, Y.P. and Hayden, M.R. (1995) SexDependent Mechanisms for Expansions and Contractions of the CAG Repeat on Affected Huntington Disease Chromosomes. American Journal of Human Genetics, 57, 343-350. http://www.ncbi.nlm.nih.gov 